\title{
Hipertansiyon Tanısı Olan Hastaların Hastalıkları Hakkındaki Bilgi Düzeyleri ve İlişkili Faktörler
}

\author{
Knowledge Level Of Hypertension Diagnosed Patients \\ About Hypertension and Related Factors \\ Aslıhan Arıkan', Abdülkadir Aydın', Hasan Çetin Ekerbiçer², Raşit Karaaytaç, \\ Yasemin Zeytinoğlư ${ }^{4}$, Gürkan Muratdağ ${ }^{5}$, Muhammed Nurullah Sezer ${ }^{6}$, Erkut Etçioğlư ${ }^{5}$, \\ Firat Karadeniz ${ }^{7}$, Aykut Kurban ${ }^{8}$ \\ ${ }^{1}$ Sakarya Üniversitesi Eğitim ve Araştırma Hastanesi, Aile Hekimliği, Sakarya \\ ${ }^{2}$ Sakarya Üniversitesi Tip Fakültesi, Halk Sağlı̆̆ı AD, Sakarya \\ ${ }^{3}$ Geyve Aile Sağlı̆̆ı Merkezi, Sakarya. \\ ${ }^{4}$ Kaynarca Yildız Aile Sağhı̆̆ Merkezi, Sakarya \\ ${ }^{5}$ Hendek 3 Nolu Aile Sağlğ̆ı Merkezi, Sakarya \\ ${ }^{6}$ Akyazı 1 Nolu Aile Sağlı̆̆ı Merkezi, Sakarya \\ ${ }^{7}$ Serdivan Yazlık Aile Sağlığı Merkezi, Sakarya \\ Yazışma Adresi / Correspondence: \\ Abdülkadir Aydın \\ Sakarya Üniversitesi Eğitim ve Araştırma Hastanesi Merkez Kampüsü / Sakarya \\ T: +905324308624 E-mail : drabkaay@gmail.com \\ Geliş Tarihi / Received : 31.05.2020 Kabul Tarihi / Accepted : 29.06.2020 \\ Aslıhan Arıkan, https://orcid.org/0000-0001-9718-1204 \\ Abdülkadir Aydın, https://orcid.org/0000-0003-0663-586X \\ Hasan Çetin Ekerbiçer, https://orcid.org/0000-0003-0064-3893 \\ Raşit Karaaytaç, https://orcid.org/0000-0002-6565-1731 \\ Yasemin Zeytinoğlu, https://orcid.org/0000-0002-2881-9638 \\ Orcid : \\ Gürkan Muratdağı, https://orcid.org/0000-0002-9629-3973 \\ Muhammed Nurullah Sezer, https://orcid.org/0000-0002-6398-8728 \\ Erkut Etçioğlu, https://orcid.org/0000-0002-8117-7929 \\ Furat Karadeniz, https://orcid.org/0000-0003-4478-863X \\ Aykut Kurban, https://orcid.org/0000-0003-3905-2855
}

( Sakarya Tip Dergisi / Sakarya Med J 2020, 10(Özel Sayı):33-40 ) DOI: 10.31832/smj.745870

$\ddot{O} z$

Amaç Bu çalıșmada; hipertansiyon hastalarının, hastalıkları hakkında bilgi düzeyleri ve ilișkili faktörlerin ortaya konması amaçlandı.

Katılımcılara kişisel bilgilere yönelik sorular ve hipertansiyon bilgi düzeyi ile ilgili doğru ve yanlş̧ önermeler içeren anket formu uygulanarak, birbirleri arasında ilişki olup olmadığı değerlendirildi. İstatistiksel anlamlılık düzeyini belirlemek amacıyla, \%95 güven aralığı ve $\mathrm{p} \leq 0,05$ anlamlı kabul edildi.

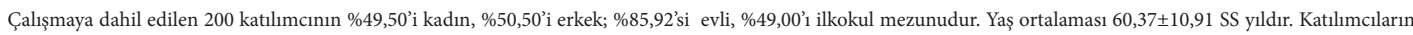
aldığı ortalama toplam puan $18,19 \pm 3,23^{\prime}$ tür. İlaç uygunluğu alt boyutunda, ortaokul, lise, üniversite ve üzeri mezun grubunun bilgi düzeyi; ilkokul ve altı grubundan anlamlı olarak daha yüksek saptandı $(\mathrm{p}=0,028)$. Lise ve üstü eğitime sahip olan katılımcıların, ortaokul ve altı eğitim düzeyine sahip katılımcllara göre istatistlksel anlamlı bir şekilde kullandıkları ilaç isimlerini daha fazla bildikleri görüldü $(\mathrm{p}=0,002)$. İlaçlarını düzenli kullananların ise tıbbi tedavi alt boyutundan aldıkları puan ortalamasının düzenli kullanmayanlardan anlamlı düzeyde yüksek olduğu görüldü $(\mathrm{p}=0,034)$. Kullandıkları ilacın adını bilenlerin toplam puan $(\mathrm{p}<0,001)$, tanım $(\mathrm{p}=0,001)$ ve tıbbi tedavi $(\mathrm{p}=0,010)$ alt boyutlarından aldıkları puanlarının anlamlı olarak yüksek olduğu görüldü.

Sonuç Hipertansiyon hastalarının, hastalıklarına dair bilgi düzeyleri ve ilișkili faktörler çeșitlilik göstermektedir. Hastalığın etkin yönetimi için hastaların bilgi düzeyleri yükseltilmelidir. Etkin yönetime engel olan diğer olası faktörlerin ortaya konması ve çözümlenmesi gerekmektedir.

Anahtar Hipertansiyon; Bilgi Düzeyi Ölçeği; Tedavi; Hastalık Bilgisi

Kelimeler

Abstract

Objective The aim of this study was to determine the knowledge levels of hypertension patients and related factors.

Materials

A questionnaire including questions about personal information and suggestions about the knowledge of hypertension was applied to the participants. The relationship between each other was evaluated.To determine the level of statistical significance, $95 \%$ confidence interval and $p \leq 0.05$ were considered significant.

Of the 200 participants included in the study, $\% 49.50$ were female and $\% 50.50$ were male; $\% 85.92$ were married and $\% 49.00$ were primary school graduates. The mean age was $60.37 \pm 10.91$ $S D$. In the drug compliance subdimension, the level of knowledge of the group of graduates of secondary school, high school, university and above; It was significantly higher than the primary and below groups ( $p=0.028$ ). It was seen that the participants who had high school and higher education knew the names of the drugs that they used statistically meaningfully more than the participants with middle and lower education levels $(p=0.002)$. It was seen that the mean score of the patients receiving medication regularly from the medical treatment subdimension was significantly higher than those who did not use it regularly $(p=0.034)$. The total score $(p<0.001)$, definition $(p=0.001)$ and medical treatment $(p=0.010)$ subdimension scores of those who knew the name of the drug they used were significantly higher.

Conclusion The knowledge levels and related factors of hypertension patients vary. Knowledge levels of patients should be increased for effective management of the disease. Other possible factors that prevent effective management need to be identified and resolved.

Key words Hypertension; Knowledge Level Scale; Treatment; Disease Information 


\section{GIIRIŞ}

Dünya çapında, 2000 yılından itibaren bulaşıcı olmayan hastalıklara bağlı ölüm sayısı giderek artmıştır. Tüm dünyada 2012 yılında gerçekleşen ölümlerin \%46,2'si yani 17,7 milyon ölüm bulaşıcı olmayan hastalıkların ana nedeni olan kardiyovasküler hastalıklar nedeniyle gerçekleşmiştir. ${ }^{1} \mathrm{Bu}$ ölümlerin 9,4 milyonu da hipertansiyon komplikasyonları nedeniyle olmuştur. ${ }^{2}$

Normal değerlerin üzerinde kan basıncı değerleri, kardiyovasküler ve renal hastalıklar için ana risk faktörü olmakla birlikte dünya çapında ölüm ve engelliliğin de ana etkenidir. ${ }^{3}$ Global hastalık yükü araştırması (Global Burden of Disease, GBD) sonuçlarına göre 2013 yılında olduğu gibi 2015 'te de yine hipertansiyon, tüm dünyada metabolik risk faktörlerinden en önemlisi olarak belirtilmiştir. ${ }^{4}$

Hipertansiyon prevalansı, genel toplumda \%30-45 arasinda değişmektedir. ${ }^{5}$ Hipertansiyon prevalansının yükselmesi; popülasyonun büyümesi, yaşlanma ve sağlıksız diyet, aşırı alkol kullanımı, yetersiz fiziksel aktivite, obezite, sürekli strese maruz kalmak gibi davranışsal risk faktörlerine bağlanmaktadır. Diyabet, yüksek kolesterol düzeyi, obezite gibi metabolik risk faktörleri hipertansiyonun kalp hastalığı, inme, böbrek yetmezliği gibi komplikasyonlarında da artışa sebep olmaktadır. ${ }^{2}$

Hipertansiyonun daima semptom vereceği yönünde bir yanlış görüş vardır fakat hipertansiyon erken evrelerinde nadiren semptom verir ve birçok kişi bu evrelerde tanı alamaz. Baş ağrısı, nefes darlığı, göğüs ağrısı, sersemlik hissi, çarpıntı ve burun kanaması gibi semptomlara neden olabilse de bu semptomlar direkt olarak hipertansiyona işaret etmezler. Yine de bu tarz semptomları yok saymak tehlikeli olabilir. ${ }^{2}$

Hipertansiyon tedavisi bu alanın uzmanı klinisyenler tarafından reçete edilmiş olsa da, hastanın ilaçlarını kullanması ve sağlıklı yaşam tarzını benimsemesi ile en efektif tedavi sağlanabilir. ${ }^{6}$ Yaşam tarzı değişikliklerine düşük uyum zamanla ilaç kullanımını da etkileyebilir. ${ }^{5}$ Kimi hastalar ilaç kullanmayı tamamen bırakır kimisi de düzensiz alır. İlacını düzenli kullanmayan hastaların ilacı bırakma riski de yüksek olduğundan bu hastaların saptanması önemli$\operatorname{dir}^{7}$

Hipertansiyon hastalarının yarısı, tedavi başlandığı ilk yılda ilaç almayı bırakır. ${ }^{7}$ Daha sorunlu olduğu düşünülen bir hasta grubu olan tedaviyi kesen grup ise kasten kesmiştir ve tedaviye geri başlamaları zordur. ${ }^{5}$ Hastaların yaklaşık \%10'u da ilaçlarını almayı unutmaktadır. ${ }^{7}$ Hipertansiyon hastalarının, hastalığı ve tedaviyi yanlış anlaması, herhangi bir semptomu olmamasından dolayı hastalığı reddetmesi, ilaç kullanımının sağlığın kötüye gidişi olarak algılaması, beklenmeyen ilaç yan etkileri ve hastanın tedaviye isteksizliği gibi bilgi düzeyinde olan eksiklikler nedeniyle tedaviye uyumsuzluk artmaktadir. ${ }^{8}$

Hipertansiyon hastalığg hakkında bilgi düzeyi arttıkça, buna paralel olarak hipertansiyon tanısı, tedavisi ve kontrol altına alma oranları da artacaktır. İnsanların hipertansiyon hastalığ hakkında bilgi düzeylerindeki eksikliklerin saptanması, bu eksiklikleri gidermeye ve geliştirmeye yardımcı olacaktır. ${ }^{9}$ Bu çalışmanın amacı; hipertansiyon hastalarının, hastalıkları ile ilgili bilgi düzeylerini ölçmek ve hastalıkla ilişkili faktörleri belirlemektir.

\section{GEREÇ ve YÖNTEMLER}

Tanımlayıcı ve kesitsel nitelikteki bu çalışma 1 Mayıs 2019 - 30 Haziran 2019 tarihleri arasında, T.C. Sağlık Bakanlığ 1 Sakarya Üniversitesi Eğitim ve Araştırma Hastanesi ve Sakarya'da bulunan altı farklı aile sağlığı merkezinde yapılmıştır. Herhangi bir nedenle hastaneye veya aile sağlığı merkezlerine başvuran, bir sağlık kuruluşu veya hekim tarafından hipertansiyon tanısı konmuş ve çalışmamıza katılmayı kabul eden 18 yaş ve üzeri toplam 200 kişi araştırma kapsamında değerlendirilmiştir. Sakarya Üniversitesi Tıp Fakültesi Girişimsel Olmayan Araştırmalar Etik Kurulunun 05.01.2018 tarih ve E.1466 sayılı izni ile çalışmaya başlanmıştır. Araştırmanın bütçesi araştırıcılar tarafından 
karşılanmıştır.

Çalışmaya katılan kişilere daha önceden hazırlanan sosyodemografik özelliklerinin sorgulandığı kişisel bilgi formu ve hipertansiyon bilgi düzeyini sorgulayan Hipertansiyon Bilgi Düzeyi Ölçeği (Hypertension Knowledge Level Scale, HK-LS) uygulandi. Bu formlar anketle ilgili gerekli bilgiler verildikten sonra sözlü onamları alındıktan sonra daha önceden bu konu hakkında eğitim almış olan hekim ve hemşireler tarafından yüz yüze görüşme yöntemi ile dolduruldu. Çalışmaya katılan bireylere katılımda gönüllülük esasının olduğu, istemedikleri halde katılımlarına son verebilecekleri, çalışmanın kim tarafından ve neden yapıldı$\breve{g}$, toplanan verilerin sadece bilimsel amaçlı kullanılacağ ve kişinin adı ve soyadı gibi kişisel bilgilerinin alınmayaca$\breve{g}$ g konusunda sözel olarak bilgi verildi.

Kişisel bilgi formu, hipertansiyon hastalarının hipertansiyona dair bilgi düzeyleri ve bağlantılı durumları ortaya koyabilmek için, araştırmacının hazırladığı; gönüllülerin cinsiyet, medeni hal, yaş, eğitim düzeyi, aktif çalışma durumu gibi özelliklerini, ilaç adını bilme ve kulanma sıklığı, kaç yıldır tansiyon hastası olduğu sorularını içeren anket formudur.

Erkoç ve ark. (2012) tarafından geliştirilen ve güvenirlik, geçerlik analizi de yapılan Hipertansiyon Bilgi Düzeyi Ölçeği (HK-LS, Hypertension Knowledge Level Scale) yetişkinlerde hipertansiyon bilgi düzeyini ölçmek amaçlı geliştirilmiştir. Ölçekte hipertansiyona dair dokuz yanlış on üç doğru olmak üzere toplam yirmi iki tane doğru ve yanlış bilgileri içeren önermeler verilmektedir ve kişinin doğru, yanlış veya bilmiyorum seçeneklerinden birini işaretlemesi istenmektedir. Ölçek 6 alt grup içermektedir. Bunlar tanım, medikal tedavi, ilaç kullanımı, yaşam tarzı, diyet ve komplikasyonlar ile ilgilidir. Ölçekteki sırasıyla hipertansiyon tanımına dair iki, medikal tedaviye dair dört, ilaç kullanımına dair dört, yaşam tarzı değişikliklerine dair beş, diyete dair iki, komplikasyonlara dair ise dört önerme mevcuttur. Her doğru verilen yanıt bir puan etmektedir.
Ölçekten alınabilecek maksimum puan yirmi iki, minimum puan sifirdır. Alt boyutlardan alınacak maksimum puanlar; tanımlama için iki, medikal tedavi için dört, ilaç kullanımı için dört, yaşam tarzı için beş, diyet için iki ve komplikasyon için beştir. Ölçekten alınan puan arttıkça hipertansiyon bilgi düzeyi arttığı yönünde yorumlanmaktadir. $^{10}$

Çalışmamızda bu ölçekteki maddelerin ayrıntılı analizi ve ölçek puanlarının diğer değişkenlerle olan karşılaştııılması ele alınmıştır.

\section{İstatistiksel Değerlendirme}

Veriler değerlendirilirken, sürekli değişkenlerin normal dağılıma uyup uymadığı Kolmogrov - Smirnov ile değerlendirilmiş; normal dağılıma uyan verilerin tanımlayıcı istatistikleri ortalama \pm standart sapma olarak verilmiştir. Normal dağılıma uymayan verilerin tanımlayıcı istatistikleri ortanca, çeyreklikler, en büyük, en küçük değer olarak verilmiştir. Nitel verilerin tanımlayıcı istatistikleri ise sayı ve yüzde olarak özetlenmiştir. Niteliksel verilerin karşılaştırılmasında pearson ki kare testi kullanılmıştır. Normal dağılıma uymayan sürekli değişkenlerin gruplar arası karşılaştırılmasında Mann Whitney U (iki grup aras1) Kruskal Wallis testi (ikiden fazla grup) uygulanmıştır. Normal dağılıma uyan sürekli verilerin gruplar arası karş1laştırmasında ise student T testi ((iki grup arası) ve ANOVA (ikiden fazla grup) kullanılmıştır. Çalışmada kullanılan ölçeğin iç tutarlılığını değerlendirmek için Cronbach alpha katsayısından yararlanılmıştır. İstatistiksel analizler için SPSS 20.0 (SPSS Inc, Chicao, IL, USA) paket programı kullanılmıştır. İstatistiksel önemlilik düzeyi $\mathrm{p} \leq 0,05$ olarak kabul edilmiştir.

\section{BULGULAR}

Çalışmamıza 99 (\%49,50) kadın, 101 (\%50,50) erkek olmak üzere toplam 200 kişi katılmıştır. Katılan 200 kişinin 6’sı (\%3) 18-40 yaş arası, 123'ü $(\% 61,80)$ 41-64 yaş arası, 70 'i $(\% 34,20) 65$ yaş ve üzeri idi. Bir kişinin ise yaş verisi

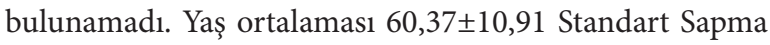


(SS) yıl idi. Evli olan katılımcilar toplam katılımciların \%85,92'sini, ilkokul mezunu katılımclar ise \%49,50'sini oluşturmaktaydı. Katılımcıların \%78'i çalışmıyordu. Hastalık süresi 10 yıldan fazla olanlar toplam katılımciların \%38,07'si, 5-10 yıl arası olanlar \%32,99'u idi. Hastaların \%79’u ilaçlarını her gün kullanıyor, \%56,73’ü ilaç adlarını bilmiyordu. Katılımcıların ölçekten aldığı ortalama toplam puan $18,19 \pm 3,23$ 'tür.

Tablo 1. Katılımcıların Hipertansiyon Bilgi Düzeyi Ölçeği Maddelerine Verdikleri Yanıtların Yüzde Dağılımları

\begin{tabular}{|c|c|c|c|}
\hline & $\mathrm{D}(\%)$ & $\mathrm{Y}(\%)$ & B (\%) \\
\hline $\begin{array}{l}\text { Küçük ya da büyük tansiyon yüksekliği yüksek } \\
\text { tansiyondur. }\end{array}$ & 77,50 & 5,50 & 17 \\
\hline $\begin{array}{l}\text { Küçük tansiyon yüksekliği de tansiyon yüksek- } \\
\text { liğini gösterir. }\end{array}$ & 65,50 & 9 & 25,50 \\
\hline $\begin{array}{l}\text { Yüksek tansiyon yaşlanmanın normal bir } \\
\text { parçasıdır, bu yüzden herhangi bir tedavi } \\
\text { gerektirmez. }\end{array}$ & 11,50 & 77 & 11,50 \\
\hline $\begin{array}{l}\text { İlaçlar yüksek tansiyon hastalarının tansi- } \\
\text { yonunu kontrol altında tutuyorsa yaşam biçim- } \\
\text { lerini değiştirmelerine gerek yoktur. }\end{array}$ & 30,50 & 64 & 5,50 \\
\hline $\begin{array}{l}\text { Yüksek tansiyonu olanlar yaşam biçimlerini } \\
\text { değiştirirlerse, ilaç almalarına gerek kalmaz. }\end{array}$ & 29 & 57,50 & 13,50 \\
\hline $\begin{array}{l}\text { Yüksek tansiyon ilaçları kişinin kendisini iyi } \\
\text { hissettiği şekilde alınmalıdır. }\end{array}$ & 26,50 & 67 & 6,50 \\
\hline Yüksek tansiyon ilacı her gün alınmalıdır. & 92 & 5 & 3 \\
\hline $\begin{array}{l}\text { Yüksek tansiyonu olanlar sadece kendilerini } \\
\text { hasta hissettiği zaman yüksek tansiyon ilaçlarını } \\
\text { almalıdır. }\end{array}$ & 11,50 & 84,50 & 4 \\
\hline $\begin{array}{l}\text { Yüksek tansiyonu olanlar ilaçlarını ömür boyu } \\
\text { kullanmalıdır. }\end{array}$ & 85 & 7 & 8 \\
\hline $\begin{array}{l}\text { Yüksek tansiyonu olanlar için en iyi yemek } \\
\text { pişirme yöntemi kızartmadır. }\end{array}$ & 3 & 91 & 6 \\
\hline $\begin{array}{l}\text { Yüksek tansiyonu olanlar için en iyi yemek } \\
\text { pişirme yöntemi haşlama ve izgaradır. }\end{array}$ & 89,50 & 4 & 6,5 \\
\hline $\begin{array}{l}\text { Yüksek tansiyonu olanlar ilaçlarını düzenli kul- } \\
\text { landığı sürece istedikleri kadar tuzlu yiyebilirler. }\end{array}$ & 4 & 94 & 2 \\
\hline $\begin{array}{l}\text { Yüksek tansiyonu olanlar, bol bol sebze ve } \\
\text { meyve yemelidir. }\end{array}$ & 93,50 & 3 & 3,50 \\
\hline $\begin{array}{l}\text { Yüksek tansiyonu olanlar için en iyi et çeşidi } \\
\text { kırmızı ettir. }\end{array}$ & 15 & 73 & 12 \\
\hline $\begin{array}{l}\text { Yüksek tansiyonu olanlar için en iyi et çeşidi } \\
\text { beyaz ettir. }\end{array}$ & 85,50 & 5 & 9,50 \\
\hline Yüksek tansiyonu olanlar sigara içmemelidirler. & 87,50 & 8 & 4,50 \\
\hline Yüksek tansiyonu olanlar alkol alabilirler. & 6,50 & 85 & 8,50 \\
\hline $\begin{array}{l}\text { Tedavi edilmeyen yüksek tansiyon, inme nedeni } \\
\text { olabilir. }\end{array}$ & 93,50 & 2 & 4,50 \\
\hline $\begin{array}{l}\text { Tedavi edilmeyen yüksek tansiyon, kalp krizi } \\
\text { gibi kalp problemlerine yol açabilir. }\end{array}$ & 96 & 1,50 & 2,50 \\
\hline
\end{tabular}

\begin{tabular}{|l|c|c|c|}
\hline $\begin{array}{l}\text { Tedavi edilmeyen yüksek tansiyon, erken yaşta } \\
\text { ölümlerin nedeni olabilir. }\end{array}$ & 94 & 2,50 & 3,50 \\
\hline $\begin{array}{l}\text { Tedavi edilmeyen yüksek tansiyon, böbrek } \\
\text { yetmezliği nedeni olabilir. }\end{array}$ & 81 & 3,50 & 15,50 \\
\hline $\begin{array}{l}\text { Tedavi edilmeyen yüksek tansiyon, görme } \\
\text { bozukluğu nedeni olabilir. }\end{array}$ & 85,50 & 3 & 11,50 \\
\hline
\end{tabular}

D: Doğru, Y: Yanlış, B: Bilmiyorum, Doğru seçenekler koyu olarak belirtilmiştir.

\begin{tabular}{|c|c|c|c|}
\hline & $\mathrm{D}(\%)$ & $\mathrm{Y}(\%)$ & $\mathrm{B}(\%)$ \\
\hline \multirow{4}{*}{$\begin{array}{l}\text { Toplam } \\
\text { puan }\end{array}$} & Kullanmiyor $(\mathrm{n}=3)$ & $16,33 \pm 2,30$ & \multirow{4}{*}{0,054} \\
\hline & $\begin{array}{l}\text { Haftanın çoğu günü kullanmıyor } \\
\qquad(\mathrm{n}=6)\end{array}$ & $15,67 \pm 1,86$ & \\
\hline & $\begin{array}{l}\text { Haftanın çoğu günü kullanıyor } \\
\qquad(\mathrm{n}=13)\end{array}$ & $18,54 \pm 1,76$ & \\
\hline & Her gün kullanıyor $(\mathrm{n}=83)$ & $18,01 \pm 3,43$ & \\
\hline \multirow{4}{*}{$\begin{array}{l}\text { Tanım alt } \\
\text { boyutu }\end{array}$} & Kullanmiyor & $1,33 \pm 1,15$ & \multirow{4}{*}{0,807} \\
\hline & Haftanın çoğu günü kullanmıyor & $1,17 \pm 0,75$ & \\
\hline & Haftanın çoğu günü kullanıyor & $1,15 \pm 0,89$ & \\
\hline & Her gün kullanıyor & $1,35 \pm 0,78$ & \\
\hline \multirow{4}{*}{$\begin{array}{l}\text { Tibbi tedavi } \\
\text { alt boyutu }\end{array}$} & Kullanmiyor & $2,33 \pm 0,57$ & \multirow{4}{*}{$0,004^{* *}$} \\
\hline & Haftanın çoğu günü kullanmıyor & $2,17 \pm 1,17$ & \\
\hline & Haftanın çoğu günü kullanıyor & $3,46 \pm 0,77$ & \\
\hline & Her gün kullanıyor & $3,41 \pm 0,85$ & \\
\hline \multirow{4}{*}{$\begin{array}{l}\text { İlaç } \\
\text { uygunluğu } \\
\text { alt boyutu }\end{array}$} & Kullanmiyor & $2,00 \pm 1,00$ & \multirow{4}{*}{0,125} \\
\hline & Haftanın çoğu günü kullanmıyor & $2,00 \pm 1,26$ & \\
\hline & Haftanın çoğu günü kullanıyor & $3,15 \pm 0,80$ & \\
\hline & Her gün kullanıyor & $2,89 \pm 1,13$ & \\
\hline \multirow{4}{*}{$\begin{array}{l}\text { Yaşam tarzı } \\
\text { alt boyutu }\end{array}$} & Kullanmiyor & $4,67 \pm 0,57$ & \multirow{4}{*}{0,982} \\
\hline & Haftanın çoğu günü kullanmıyor & $4,67 \pm 0,51$ & \\
\hline & Haftanın çoğu günü kullanıyor & $4,61 \pm 0,65$ & \\
\hline & Her gün kullanıyor & $4,50 \pm 0,80$ & \\
\hline \multirow{4}{*}{$\begin{array}{l}\text { Diyet alt } \\
\text { boyutu }\end{array}$} & Kullanmiyor & $1,00 \pm 1,00$ & \multirow{4}{*}{0,319} \\
\hline & Haftanın çoğu günü kullanmıyor & $1,33 \pm 0,81$ & \\
\hline & Haftanın çoğu günü kullanıyor & $1,76 \pm 0,43$ & \\
\hline & Her gün kullanıyor & $1,50 \pm 0,67$ & \\
\hline \multirow{4}{*}{$\begin{array}{l}\text { Komp- } \\
\text { likasyon } \\
\text { alt boyutu }\end{array}$} & Kullanmiyor & $5,00 \pm 0,00$ & \multirow{4}{*}{0,524} \\
\hline & Haftanın çoğu günü kullanmıyor & $4,33 \pm 0,81$ & \\
\hline & Haftanın çoğu günü kullanıyor & $4,38 \pm 0,76$ & \\
\hline & Her gün kullanıyor & $4,34 \pm 1,17$ & \\
\hline
\end{tabular}

Katılımcıların hipertansiyon ilaçlarını kullanma sıklıklarına göre Hipertansiyon Bilgi Düzey Ölçeğinin tıbbi tedavi 
alt boyutundan aldıkları puanlar karşılaştırıldı̆̆ında; ilacını çoğu günlerde kullandığını belirtenlerin, çoğu günlerde kullanmadığını belirtenlerden; istatistiksel anlamlı olarak daha yüksek "tıbbi tedavi" alt boyut puan ortalamalarına sahip olduğu görüldü (p:0,004) (Tablo 2). Bununla birlikte; ilacını her gün kullananları "düzenli kullanan grup”, aksatarak kullananlar ve kullanmayanlar "düzensiz kullanan grup" olarak ele alındığında da bu iki grubun "tıbbi tedavi” alt boyutu puanları arasında anlamlı fark saptandı. Düzenli kullanan grubun daha yüksek puan ortalamasına sahip olduğu görüldü $(\mathrm{p}=0,034)$.

Katılımcıların, kullandıkları hipertansiyon ilaçlarının adlarını bilip bilmemelerine göre Hipertansiyon Bilgi Düzeyi Ölçeğinden aldıkları toplam puan, tanım ve tıbbi tedavi alt boyut puanları arasında istatistiksel anlamlı bir fark bulunmuştur. Kullandıkları hipertansiyon ilaçlarının isimlerini bilen katılımcılar Hipertansiyon Bilgi Düzey Ölçeğinden istatistiksel olarak anlamlı daha yüksek puan almışlardır. Benzer şekilde; ilaçlarının isimlerini bilen katılımcılar ölçeğin tanım ve tıbbi tedavi alt boyutundan istatistiksel anlamlı bir şekilde daha yüksek puan almıştır (Tablo 3).

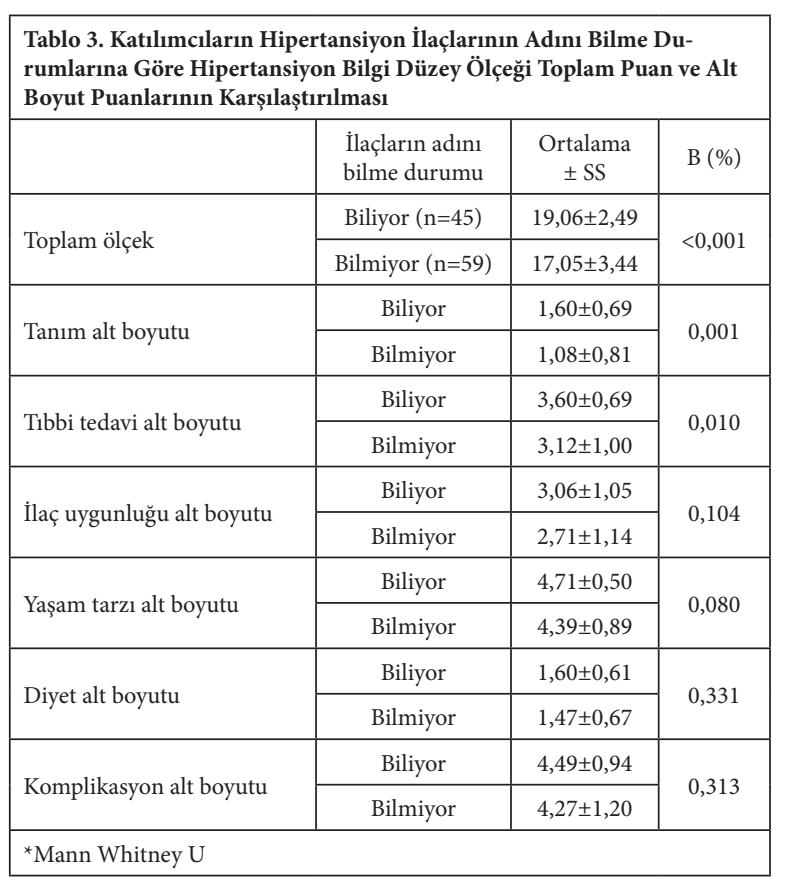

Katılımcıların eğitim düzeyleri ile kullandıkları hipertansiyon ilacının adını bilme durumları karşılaştırıldığında istatistiksel olarak anlamlı fark bulunmuştur. Farkın hangi grup/gruplardan kaynaklandığını anlamak için yapılan post-hoc testler sonucunda lise ve üstü eğitime sahip olan katılımcıların ortaokul ve altı eğitim düzeyine sahip kişilere göre istatistiksel anlamlı bir şekilde ilaç isimlerini daha fazla bildikleri görülmüştür (Tablo 4). Bu soruya 104 katılımcı cevap vermiştir. Analiz bu katılımcı sayısına göre yapılmıştır.

\begin{tabular}{|c|c|c|c|c|}
\hline \multicolumn{5}{|c|}{$\begin{array}{l}\text { Tablo 4. Katılımcıların Eğitim Düzeylerine Göre Hipertansiyon İl- } \\
\text { açlarının Adını Bilme Durumlarının Karşılaştırılması }\end{array}$} \\
\hline & Evet & Hayır & Toplam & $\mathrm{p}^{*}$ \\
\hline Okuryazar değil & 3 & 13 & 16 & \multirow{5}{*}{0,002} \\
\hline İlkokul & 12 & 29 & 41 & \\
\hline Ortaokul & 8 & 7 & 15 & \\
\hline Lise & 12 & 7 & 19 & \\
\hline Üniversite ve üzeri & 10 & 3 & 13 & \\
\hline Toplam & 45 & 59 & 104 & \\
\hline
\end{tabular}

\section{TARTIŞMA}

Katılımcıların bu ölçekten aldıkları toplam puan ortalamas1 18,19 $\pm 3,23$ SS olarak hesaplandi. Hipertansiyon tanısı varlığını gözetmeksizin genel erişkin popülasyonda yapılan bir çalışmada, katılımcıların hipertansiyon bilgi düzeyi puan ortalaması 17,71 $\pm 3,77$ SS bulunmuştur. ${ }^{10}$ Yine Yunanistan'da yapılan, bir sağlık kurumuna herhangi bir nedenle başvurmuş 68 hastada yapılan bir çalışmada, hipertansiyon hastası olanların puan ortalaması 15,76 $\pm 2,40$ SS olarak bulunmuştur. ${ }^{11}$ Literatürde farklı popülasyonlarda yapılan benzer çalışmalarda birçok farklı sonuç saptanmıştır. Çalışmamızda daha yüksek puan ortalaması elde edilmesinin; katılımcılarımızın tamamının hipertansiyon hastası olmaları ve birinci ve üçüncü basamak sağlık kurumlarında etkin yönetim yapılabildiği kanaatindeyiz.

Katılımcıların ilaçlarını kullanma sıklıkları ile Hipertansiyon Bilgi Düzeyi Ölçeği 'tıbbi tedavi' alt boyutundan 
aldıkları puanlar karşılaştırıldığında; ilaçlarını düzenli kullananların 'tıbbi tedavi' alt boyutundan aldıkları puan ortalamasının düzenli kullanmayanlardan anlamlı düzeyde yüksek olduğu görüldü. Hipertansiyon tanılı bireylerin hipertansiyon bilgi düzeyini araştıran bir çalışmada en sık yanlış yapılan sorular hipertansiyonun semptomu olması gerektiği ve tansiyonları yükseldiğinde hissedecekleri konusu olmuştur. ${ }^{9}$ Katılımcıların bu düşünceleri ilaçlarını sadece semptom hissettiklerinde kullanmalarına ve ilaçlarını düzenli kullanmamalarına sebep olabilir. Ürdün'de yapılan bir araştırma da ise yüksek hipertansiyon bilgi düzeylerinin tedaviye ve yaşam tarzı değişikliklerine yüksek uyumla ilişkili olduğu görülmüştür. ${ }^{12}$

Katılımcıların yaklaşık üçte biri "İlaçlar yüksek tansiyon hastalarının tansiyonunu kontrol altında tutuyorsa yaşam biçimlerini değiştirmelerine gerek yoktur” ifadesinin doğru olduğunu düşündügünü belirtti. Bir kamu hastanesinde hipertansiyon tanılı yatan hastalar üzerinde yapılan bir araştırma sonuçlarında da benzer şekilde katılımcıların \%37,9'unun ilaç dışında doktorun önerdiği yaşam biçimi değişikliklerini uygulamadıkları belirtilmiştir. ${ }^{13}$ Bir toplum sağlığı merkezine başvuran hipertansiyon hastalarında yapılan çalışmada da katılımcıların üçte biri doktorunun önerdiği diyete uymadıklarını ve tuz kısıtlaması yapmadıklarını, kilolarını takip etmediklerini, üçte ikisi ise fiziksel aktivite yapmadıklarını bildirmişlerdir. ${ }^{14}$

Hipertansiyon yönetiminde ve komplikasyonların önlenmesinde yaşam tarzı değişikliklerinin ilaç tedavisi kadar önemli ve etkili olduğu bilinmektedir. Özellikle hipertansiyonun ilk farkedildiği ve tanısının konduğu birinci basamak sağlık kuruluşlarında hipertansiyon hastalarına hipertansiyon hastalığının fizyolojisi, süreci, tedavisi, izlemi ve yaşam tarzı değişiklikleri konusunda ayrıntılı eğitimler verilmesi; hastanın her ziyaretinde bu konular hakkında kısa hatırlatmalar yapılması ve yaşam tarzı değişikliklerini uygulayıp uygulamadıklarının sorgulanması hastaların tedaviye ve yaşam tarzı değişikliklerine uyumunu arttırabilir ve böylelikle hipertansiyon kontrol oranları daha da iyileştirilebilir.

Çalışmamızda ki bir ilginç bulgu da katılımcıların neredeyse üçte birinin "Yüksek tansiyonu olanlar yaşam biçimlerini değiştirirlerse, ilaç almalarına gerek kalmaz" ifadesine katılmasıdır. Hipertansiyon bilgi düzeyine dair yapılan bir çalışmada katılımcılar ölçekten aldıkları puana göre düşük ve yüksek bilgi düzeyi olanlar olarak ikiye ayrılmıştır. Düşük bilgi düzeyine sahip katılımcıların \%39,5'i, yüksek bilgi düzeyine sahip katılımcıların ise \%9,3'ü bu ifadeye katıldıklarını ifade etmişlerdir. ${ }^{15}$ Farklı bir çalışmada da katılımcıların \%44,2'si destekleyici tedavi kullanırken ilaç tedavisini sürdürmediklerini ifade etmişlerdir. ${ }^{13}$

Hipertansiyon çoğu zaman semptom vermemesi nedeniyle hastaların tedavi uyumlarının da düşük olduğu bir hastalıktır. Hipertansiyon tanısı alanların yarısı ilk bir yıl içinde ilaç tedavisini bırakmaktadır. İlaç tedavisine devam edenlerin bir kısmı da ilaçlarını düzenli olarak kullanmamaktadır. Çalışmamızda katılımcıların da \%21'i ilaç tedavisini her gün düzenli olarak kullanmadıklarını belirtmişlerdir. Bazı düşük riskli hastalarda ilk tedavi seçeneği yaşam tarzı değişiklikleri olabilmekle beraber; yaşam tarzı değişiklikleri ilaç tedavisinin bir alternatifi olarak görülmemelidir. Yaşam tarzı değişikliklerinin ilaç tedavisi yerine geçebileceği yönündeki yanlış algı, zaten ilaç tedavisine uyumu tam olmayan hastalarda tedaviyi tamamen bozabilir. $\mathrm{Bu}$ nedenle sağlık çalışanları tarafından; hastalarına yaşam tarzı değişikliklerinin ilaç tedavisinin alternatifi olmadığı, ilaç tedavisi ile beraber uygulandığında kan basıncını kontrol atına almaya yardımcı olduğu ve hipertansiyonun komplikasyonlarından korunmak için yardımcı olduğu anlatılmalıdir.

Bir çalışmada ilaçlarını düzenli olarak kullanan katılımc1ların istatistiksel olarak anlamlı bir şekilde hipertansiyonlarının daha fazla kontrol altında olduğu görülmüştür. ${ }^{16}$ Çalışma ve literatür verileri birlikte değerlendirildiğinde; hipertansiyonda verilen tedavinin hiçbir yakınma olmasa da düzenli olarak her gün alınması gerektiği ve tedaviye 
uyumun öneminin her doktor ziyaretinde hastalara hatırlatılması gerektiği kanaati oluşmaktadır.

Çalışmamızda daha yüksek eğitim düzeyine sahip katılımcıların kullandıkları ilaçların isimlerini daha fazla bildikleri görülmüştür. Kullandıkları hipertansiyon ilacının adını bilen katılımcılar; ölçeğin tanım, 'tıbbi tedavi' alt boyutları ve toplam ölçek puanından istatistiksel olarak anlamlı bir biçimde daha yüksek puanlar almışlardır. Katılımcıların kullandıkları ilacın adını bilmeleri; hastalıklarının farkında olmalarının yanında, hipertansiyon ve tedavisi konusunda da ilgili olduklarını ve daha fazla bilgiye sahip olduklarını göstermektedir.

Birinci basamak sağlık kurumuna herhangi bir nedenle başvuran hastalarda yapılan bir çalışmada ise; eğitim düzeyi ile hipertansiyon değerleri ile ilgili bilgi durumları arasında bir ilişki bulunamamıştır. ${ }^{17}$ Çalışmamızda ise eğitim düzeyi ile Hipertansiyon Bilgi Düzeyi Ölçeği puan düzeyi istatistiksel olarak anlamlı bulundu.

Sonuç olarak; hipertansiyon sık görülen bir hastalık olmasına rağmen henüz istenen kan basıncı kontrolü sağlanamamıştır. ${ }^{18}$ Ülkemizdeki hipertansiyon hastalarının yarısı hipertansiyon hastası olduğunu dahi bilmememektedir. ${ }^{19}$ Hipertansiyon hastası olduğunu bilen ve ilaç kullananlarda ise istenen kan basıncı oranı \%20,7 bulunmuştur. ${ }^{20}$ Çalışmamız sonucunda hipertansiyon hastalarının bilgi düzeyleri iyi durumda olmasına rağmen ülkemizde hipertansiyonun sık görülmesi ve kontrolünün yeterli olmaması, hastaların doğru bildiklerini uygulamıyor olmasıyla açıklanabilir.

Hasta uyumunu arttırabilmek için; motivasyon ile birlikte bilgilendirme, grup tedavisi, hastanın tansiyonunu kendi ölçmesi, basit yönlendirmelerle hastanın kendi tedavisini yönetebilmesi; psikolojik destek, telefonla izlem, ev ziyaretleri, sık kontrol, işyeri ve eczane işbirliği gibi müdahaleler planlanabilir.
Hastalı̆̆ın etkin yönetimi için hastaların bilgi düzeyleri yükseltilmelidir. Etkin yönetime engel olan diğer olası faktörlerin ortaya konması ve hekim, hemşire, eczac1, gereğinde uzmanlar ve diyetisyenleri içeren bir ekip ile çözümlenmesi gerekmektedir.

Etik Kurul Onayı

Bu çalışmaya Sakarya Üniversitesi Tıp Fakültesi Girişimsel Olmayan Araştırmalar Etik Kurulunun 05.01.2018 tarih ve E.1466 sayılı izni ile başlanmıştır. 
Sakarya Tip Dergisi 2020;10(Özel Sayı):33-40

ARIKAN ve Ark.,Hipertansiyon Hakkında Bilgi Düzeyleri

\section{Kaynaklar}

1. Dünya Sağllk Örgütü (DSÖ). Global Status Report on noncommunicable diseases 2014. WHO press. Geneva, Switzerland, 2014.

2. Dünya Sağllk Örgütü (DSÖ). A global brief on hypertension; Silent killer, global public health crisis. WHO press. Geneva, Switzerland, 2013.

3. Gorostidi M, Vinyoles E, Banegas JR, de la Sierra A. Prevalence of white-coat and masked hypertension in national and international registries. Hypertens Res. 2015;38(1):1-7.

4. Forouzanfar MH, Afshin A, Alexander LT, Anderson HR, Bhutta ZA, Biryukov S et al. Global, regional, and national comparative risk assessment of 79 behavioural, environmental and occupational, and metabolic risks or clusters of risks, 1990-2015: A systematic analysis for the Global Burden of Disease Study 2015. Lancet. 2016; 388(10053):1659-1724.

5. Mancia G, Fagard R, Narkiewicz K, Redon J, Zanchetti A, Böhm M et al. 2013 ESH/ESC Guidelines for the management of arterial hypertension: The task force for the management of arterial hypertension of the European Society of Hypertension (ESH) and of the European Society of Cardiology (ESC). J Hypertens. 2014; 31(7):1281-357.

6. National Institutes of Health (NIH). Your guide to lowering blood pressure. (NIH Publication No. 03-5232) U.S. Department of Health and Human Services, 2003.

7. Türkiye endokrinoloji ve metabolizma derneği (TEMD). Hipertansiyon Tanı ve Tedavi Kllavuzu. Ankara, Türkiye, 2018.

8. Joint National Committee on Prevention, Detection, Evaluation, and Treatment of High Blood Pressure (JNC). The seventh report of the joint national committee on prevention, detection, evaluation, and treatment of high blood pressure. (NIH Publication No. 03-5233). Washington, DC: U.S. Department of Health and Human Services, 2003.

9. Viera AJ. Cohen LW, Mitchell CM, Sloane PD. High blood pressure knowledge among primary care patients with known hypertension: A North Carolina Family Medicine Research Network (NC-FM-RN) study. J Am Board Fam Med. 2008; 21(4):300-8.

10. Erkoc SB, Isikli B, Metintas S, Kalyoncu C. Hypertension Knowledge-Level Scale (HKLS): A study on development, validity and reliability. Int. J. Environ. Res. Public Health. 2012;9(3):1018-1029.
11. Chatziefstratiou AA, Giakoumidakis K, Fotos NV, Baltopoulos G, Brokalaki-Pananoudak H. Translation and validation of the Greek version of the hypertension knowledge-level scale. Journal of clinical nursing. 2015;24(23-24):3417-3424.

12. Eshah NF, Al-daken LI. Assessing publics' knowledge about hypertension in a community-dwelling sample. Journal of Cardiovascular Nursing.2016; 31(2):158-165.

13. Efe D, Akça N, Kiper S, Aydın G, Gümüş K. Hipertansiyonu olan bireylerin kan basıncını düșürmeye yönelik kullandıkları destekleyici yöntemler. Spatula DD. 2012;2(4):207-212.

14. Tokem Y, Taş̧̧ı E, Yllmaz M. Hipertansiyon tanısı olan bireylerin evde hastallk yönetimlerinin incelenmesi. Turk Soc Cardiol Turkish Journal of Cardiovascular Nursing.2013; 4(5):30-40.

15. Jankowska-Polańska B, Uchmanowicz I, Dudek K, Mazur G. Relationship between patients' knowledge and medication adherence among patients with hypertension. Patient prefer adherence. 2016;10:2437-2447.

16. Zhang X, Zhu M, Dib H. H, Hu J, Tang S, Zhong T et al. Knowledge, awareness, behavior $(K A B)$ and control of hypertension among urban elderly in Western China. Int J Cardiol. 2009;137(1):9-15.

17. Oskay EM, Önsüz MF, Toğuzoğlu A. (2010). İzmir'de bir sağlik ocağı’nda başvuranların hipertansiyon hakkındaki bilgi, tutum ve görüsslerinin değerlendirilmesi. ADÜ Tip Fakültesi Dergisi. 11(1):3-9.

18. Birdane A, Erdoğan D, Uyarel H, Aksakal E, Yildız A. HT bülteni, özel sayl: Güncel kllavuzlar ıșığında hipertansiyon tanı ve tedavisi. Türk kardiyoloji derneği, hipertansiyon çalıșma grubu, HT bülteni. 2014; Yll:1.

19. Altun B, Arici M, Nergizoğlu G, Derici U, Karatan O, Turgan C et al, Turkish Society of Hypertension and Renal Diseases. Prevalence, awareness, treatment and control of hyper tension in Turkey (the PatenT study) in 2003. J Hypertens.2005; 23(10):1817-23.

20. Abacı A. Kardiyovasküler risk faktörlerinin ülkemizdeki durumu. Arch Turk Soc Cardiol. 2011;39 Suppl 4:1-5. 